\title{
Evaluation of Knowledge of Type 2 Diabetes among University Students in Punjab, Pakistan
}

\section{${ }^{a}$ Kashif Siddique, ${ }^{\text {b }}$ Ra'ana Malik}

${ }^{a}$ PhD Scholar, Department of Gender Studies, University of the Punjab Lahore, Pakistan Lecturer, Department of Gender Studies, Bahauddin Zakariya University Multan, Pakistan Email: kashif.siddique@bzu.edu.pk

${ }^{\mathrm{b}}$ Professor, Department of Gender Studies, University of the Punjab Lahore, Pakistan Email: raana.malik@yahoo.com

\begin{tabular}{l}
\hline ARTICLE DETAILS \\
\hline History: \\
Accepted 29 August 2021 \\
Available Online September 2021
\end{tabular}

\section{Keywords:}

Type 2 Diabetes, Risk Factors, Knowledge, Pakistan

\section{JEL Classification:}

I11, D81, D80

DOI: $10.47067 /$ real.v4i3.185

\section{ABSTRACT}

The aim of the study was to evaluate the level of knowledge of university students about risk factors, signs and symptoms, and impact of diabetes in Punjab, Pakistan. A cross-sectional study design was used for this study. Population of the study was students who were enrolled in public and private universities in Punjab. A multistage sampling method was used for this study. Total 1260 students were selected randomly among which 1087 respondents completed the self-administered questionnaire. Descriptive statistics and the Chi-square test were used through Statistical Package of Social Science (SPSS) version 20.o. The results of the study showed that $544(50 \%)$ respondents were females, most respondents 617 (56.7\%) were between 20-23 years old, $589(54.2 \%)$ respondents were studying at undergraduate level, 435 (40\%) respondents had poor economic status, 1006 (92.5\%) respondents were single, 813 (4.8\%) respondents never got their sugar level checked, and $696(64 \%)$ respondents had family history of diabetes. Findings of the study also indicated that most of the respondents $77.9 \%$ had inadequate knowledge about risk factors of type 2 diabetes, 73.4\% respondents had inadequate knowledge of signs and symptoms of type 2 diabetes, and $72.2 \%$ respondents had inadequate knowledge of impact of diabetes. Chi-square test showed that level of knowledge of diabetes was associated with gender $(p<.001)$, education $(p<.001)$, marital status $(p<.001)$, ever checking of sugar $(p<.001)$, and family history of diabetes $(p<.001)$. The study concluded that majority of the respondents had inadequate knowledge of diabetes. Therefore, there is a need of educational programs and awareness sessions for university students. It will be helpful in enhancing students' knowledge and reducing the prevalence of diabetes in the future of Pakistan.

(C) 2021 The authors. Published by SPCRD Global Publishing. This is an open access article under the Creative Commons AttributionNonCommercial 4.0

Corresponding author's email address: kashif.siddique@bzu.edu.pk 


\section{Introduction}

Diabetes is prevailing rapidly worldwide. Almost one person is developing diabetes in every five second (Alberti, Zimmet, \& Shaw, 2007; Federation, 2011). The rate of increase of diabetes is $170 \%$ in developing countries and 47\% in developed countries (Wild, Roglic, Green, Sicree, \& King, 2004). In the world, it is estimated that 463 million people are living with diabetes. It is predicted that by 2045 diabetic patients will be more than 700 million.

The recent National Diabetes Survey (NDSP 2016-17) shows the prevalence of diabetes in Pakistan. According to NDSP, the prevalence of diabetes is 26.3\% in Pakistan (Basit, Fawwad, Qureshi, \& Shera, 2018). The provincial pattern of prevalence is as follows: Punjab; 30.2\%, Khyber PakhtunKhwa; $13.2 \%$, Balochistan; $29.5 \%$ and Sindh; $32.3 \%$. These figures equate to approximately 27.4 million people aged 20 and above, based on the 207.77 million total population (Basit, Fawwad, \& Baqa, 2019; Basit et al., 2018). If the present situation continues, Pakistan is expected to achieve the highest prevalence of diabetes globally (Hussain \& Ali, 2016).

There are many risk factors of diabetes and they are differentiated on the basis of modifiable factors and nonmodifiable risk factor. Nonmodifiable factors include gender, ethnicity, aging, family history of diabetes (Abate \& Chandalia, 2003; Gale \& Gillespie, 2001; Valdez, Yoon, Liu, \& Khoury, 2007). As compared to females, males are more prone to develop T2D and its related complications (Gale \& Gillespie, 2001). Earlier studies have mentioned that ethnic groups like South Asians, Africans, and Americans face the burden of type 2 diabetes and more risk of onset of type 2 diabetes as compared to the European (Abate \& Chandalia, 2001; Chow, Foster, Gonzalez, \& McIver, 2012).

Nonmodifiable factors include obesity (Engelgau, Narayan, \& Herman, 2000), high abdomen fat (Lee, Bacha, \& Arslanian, 2006), unhealthy diet (Alneami \& Coleman, 2016), physical inactivity and sedentary lifestyle (Association, 2021), poor sleep quality (Gitu, 2018), skipping breakfast (Ballon, Neuenschwander, \& Schlesinger, 2019), low consumption of vegetables and fruits (Li, Fan, Zhang, Hou, \& Tang, 2014; Villegas et al., 2008), high blood pressure (M.-J. Kim, Lim, Choi, \& Park, 2015), more consumption of sweet products (Khatib, 2004), more salt intake (Radzeviciene \& Ostrauskas, 2017), stress (Harris et al., 2017; Pouwer, Kupper, \& Adriaanse, 2010), smoking (Health \& Services, 2014), high alcohol consumption (Kao, Puddey, Boland, Watson, \& Brancati, 2001), impaired glucose tolerance (Nathan et al., 2007), low birth weight (Jornayvaz et al., 2016), high cholesterol level (Seo et al., 2011; Wada, Yano, Hamano, Nabika, \& Kumakura, 2016), fried and fast food consumption (Panagiotakos et al., 2005), and pregnancy (C. Kim, Newton, \& Knopp, 2002).

The most common signs and symptoms among diabetic patients are weight loss, feeling thrust, frequent urination, blurred vision, numbness in hands and feet, weakness, decrease sexual ability (Ramachandran, 2014). The diabetic patients have more changes of complications like cardiovascular disease, retinopathy, nephropathy, neuropathy, blood pressure, infections, reduce life expectancy, and liver problems (Nathan, 1993).

According to World Health Organization, Diabetes is considered a non-communicable disease with a growing prevalence worldwide (Asif, 2014) and will become the leading cause of death globally (Mathers \& Loncar, 2006). Type 2 diabetes (T2D) affects the most productive life span, but it also begins to appear in young age (Al-Mahrooqi et al., 2013). T2D is now increasingly being diagnosed in young adults, but it is a disease that can be prevented through adopting positive health behaviors and drug therapy (Duncan, 2006; Ramkumar \& Tandon, 2013; Sridhar, Putcha, \& Lakshmi, 2010). Positive health behaviors including physical activity and healthy food choice play a vital role in the control and 
prevention of T2D, and is associated with lower risk of T2D (Dunkley et al., 2014; Mongiello, Freudenberg, Jones, \& Spark, 2016). Knowledge forms the foundation for the acceptance of positive health behaviors and these behaviors changes at the time of young adults enable them to be protected from disease throughout their lives (Katulanda et al., 2011; N. Khan, Gomathi, Shehnaz, \& Muttappallymyalil, 2012). Therefore, it is important that young adults are well informed about preventive measures for T2D, its onset risk factors, signs and symptoms and its impact.

Most of the studies have been conducted in Pakistan to measure the level of knowledge or awareness among general population as well as diabetic patients (Gillani et al., 2018; R. M. A. Khan, CH, \& Ahmad, 2009; Mangi et al., 2018; Masood, Saleem, Hassan, Zia, \& Khan, 2016; Shahzad et al., 2018; ur Rehman et al., 2014; Zuhaid, Zahir, \& Diju, 2012) expect for a few studies conducted among medical students about assessment of knowledge of diabetes (Khosa, Mukhtar Mehboob, Sana, \& Khosa; Phil \& Hafeez, 2016). Unfortunately, diabetes knowledge regarding risk factors of type 2 diabetes, signs and symptoms of diabetes and impact of diabetes are not well documented among university students in Pakistan. Therefore, this study has been conducted to evaluate the diabetes knowledge among university students in Punjab, Pakistan.

\section{Materials and Methods}

The cross-sectional study was conducted among university students in Punjab, Pakistan from October 2019 to December 2019. The respondents were selected by multistage sampling technique. At first stage, three of nine divisions of Punjab province were randomly sampled (i.e. Lahore, Faisalabad, and Multan). At second stage, three public universities (i.e. University of the Punjab Lahore, Government College University Faisalabad, and Bahauddin Zakariya University Multan) and three private universities (University of Lahore, University of Faisalabad, and Institute of Southern Punjab Multan) were sampled from each selected division. At third stage, three faculties were sampled from each selected university (i.e. Faculty of Arts and Social Science, Faculty of Natural Science, and Faculty of Management Sciences). At fourth stage, about 70 students were randomly sampled in each selected faculty of the selected public and private universities. Finally, a total of 1260 university students were randomly selected for the study. Out of them, 173 did not completely fill the questionnaire. After elimination of the unfilled questionnaire, total 1087 respondents' data were used for analysis.

\subsection{Data Collection}

A structured self-administered online questionnaire with closed-ended questions about risk factors of type 2 diabetes having 24-items (see table 2), signs and symptoms having 11-items (see table 3) and impact of diabetes having 8-items (see table 4) were developed after extensive literature review. The questions responses were "don't know", “no", and "yes". If the respondents reported incorrect answer, then their score was coded ' 0 ' and if they reported correct answer then their sore was coded ' 1 '. In diabetes knowledge questionnaire some statements of the questions were negatively stated (e.g. feeling less thirst). Demographic characteristics of the respondents including gender, age groups, level of education, economic status, marital status, ever checked sugar level, and family history of diabetes (see table 1). The questionnaire was pretested with a group of 120 university students to identify problems if any, related to questions, words and statements. Next that identified inaccuracies and inconsistences were revised. The reliability of the total diabetes knowledge questionnaire score was assessed by Cronbach's alpha with a value of 0.85 in this research study. Face validity of the questionnaire was checked by two experts, one medical sociologist and one diabetologist and they recommended some changes and the researcher incorporated it.

The research study is the part of PhD research project that was approved from the Doctoral Programme Coordination Committee, University of the Punjab Lahore, Pakistan for ethical clearance 
(Reference letter no 6777-ACAD dated 12-09-2019). At the start of the questionnaire, the researcher gave the consent form and detail of the study objective. Every individual had the right to accept it or reject it. Those individuals who accepted it they further continued the questionnaire. Privacy and confidentiality of the respondents were ensured by the researcher by not asking questions regarding their names, contact numbers, addresses.

\subsection{Data Analysis}

The objective of the study was to evaluate the level of knowledge about diabetes and its association with demographic characteristics of the respondents. Therefore, frequencies, percentages and Chi-square test was applied through SPSS version 20.0 and $\mathrm{p}<0.5$ was considered statistically significant.

\section{Results}

In all, $544(50 \%)$ males and $543(50 \%)$ were in the data analysis. The results indicated that most respondents 617 (56.7\%) were between 20-23 years old, 589 (54.2\%) respondents were studying at undergraduate level, 435 (40\%) respondents had poor economic status, 1006 (92.5\%) respondents were single, $813(4.8 \%)$ respondents never got their sugar level checked, and 696 (64\%) respondents had family history of diabetes (Table 1 ).

\begin{tabular}{|c|c|c|}
\hline Variables & Total & Percentage \\
\hline \multicolumn{3}{|l|}{ Gender } \\
\hline Male & 544 & 50 \\
\hline Female & 543 & 50 \\
\hline \multicolumn{3}{|l|}{ Age } \\
\hline Less than 20 & 324 & 29.8 \\
\hline $20-23$ & 617 & 56.7 \\
\hline $24-29$ & 146 & $13 \cdot 5$ \\
\hline \multicolumn{3}{|l|}{ Education } \\
\hline Intermediate & 314 & 28.8 \\
\hline Undergraduate & 589 & 54.2 \\
\hline Graduate & 137 & 12.6 \\
\hline M.Phil./PhD & 47 & 4.4 \\
\hline \multicolumn{3}{|l|}{ Economic Status } \\
\hline Poor & 435 & 40 \\
\hline Middle & 425 & 39 \\
\hline Rich & 227 & 21 \\
\hline \multicolumn{3}{|l|}{ Marital Status } \\
\hline Single & 1006 & 92.5 \\
\hline Married & 81 & $7 \cdot 5$ \\
\hline \multicolumn{3}{|c|}{ Ever Check Blood Sugar } \\
\hline No & 813 & 74.8 \\
\hline Yes & 274 & 25.2 \\
\hline \multicolumn{3}{|c|}{ Family History of Diabetes } \\
\hline No & 696 & 64 \\
\hline Yes & 391 & 36 \\
\hline
\end{tabular}


Majority of respondents incorrectly reported about knowledge of risk factors of T2D and they did not know that being Asian, more abdomen fat, less physical activity, sleep less than 7-8 hours, aging, poor dietary patterns 2-3 serving of fruits, pregnancy, impaired glucose tolerance, low birth weight were risk factors of $\mathrm{T} 2 \mathrm{D}$ onset. On the other side, most of the respondents reported correctly that gender (male), overweight or obesity, high blood pressure, more sweets products intake, sedentary lifestyle, used more salt, stress, smoking and alcohol use, breakfast skipping, high cholesterol level and more intake of fast food were the risk factors of T2D (Table 2).

Table 2: Responses of Participants Regarding Knowledge of Risk Factors of Type 2 Diabetes

\begin{tabular}{|c|c|c|c|}
\hline Sr. & Statements & $\begin{array}{l}\text { Incorrect } \\
\text { responses }\end{array}$ & $\begin{array}{l}\text { Correct } \\
\text { responses }\end{array}$ \\
\hline & & $f(\%)$ & $f(\%)$ \\
\hline 1 & $\begin{array}{l}\text { Males have more risk of onset of Type II diabetes than } \\
\text { females. }\end{array}$ & $319(29 \cdot 3)$ & $768(70.7)$ \\
\hline 2 & The Asian have high risk of onset of Type II diabetes. & $983(90.4)$ & $104(9.6)$ \\
\hline 3 & $\begin{array}{l}\text { A person who is obese or overweight has more chances of } \\
\text { onset of Type II diabetes. }\end{array}$ & $15(1.4)$ & $1072(98.6)$ \\
\hline 4 & $\begin{array}{l}\text { A person who has diabetic patients in his family has more } \\
\text { chance of risks of onset of Type II diabetes. }\end{array}$ & $955(87.9)$ & $132(12.1)$ \\
\hline 5 & $\begin{array}{l}\text { A person who has blood pressure more than 140/90 } \mathrm{mmHg} \\
\text { has more risk of onset of Type II diabetes. }\end{array}$ & $417(38.4)$ & $670(61.6)$ \\
\hline 6 & $\begin{array}{l}\text { A person who has more abdominal fat has more risk of onset } \\
\text { of Type II diabetes. }\end{array}$ & $973(89.5)$ & $114(10.5)$ \\
\hline 7 & $\begin{array}{l}\text { A person who consumes more sweets products has more } \\
\text { chance of risk of onset of Type II diabetes. }\end{array}$ & $17(1.6)$ & $1070(98.4)$ \\
\hline 8 & $\begin{array}{l}\text { A person who is doing less physical activity or do no exercise } \\
\text { has more risk of onset of Type II diabetes. }\end{array}$ & $625(57 \cdot 5)$ & $462(42.5)$ \\
\hline 9 & $\begin{array}{l}\text { A person who has not sedentary lifestyle has less risk of onset } \\
\text { of Type II diabetes. }\end{array}$ & $422(38.8)$ & $665(61.2)$ \\
\hline
\end{tabular}




\begin{tabular}{|c|c|c|c|}
\hline 10 & $\begin{array}{l}\text { A person who sleeps less than 7-8 hours has high risk of onset } \\
\text { of Type II diabetes. }\end{array}$ & $791(82.8)$ & $296(27.2)$ \\
\hline 11 & $\begin{array}{l}\text { A person whose age is increasing has high risk of onset of } \\
\text { Type II diabetes. }\end{array}$ & $883(81.2)$ & $204(18.8)$ \\
\hline 12 & $\begin{array}{l}\text { A person who has poor dietary pattern (eating more oily food, } \\
\text { fats, soft drinks etc.) has high risk of onset of Type II diabetes. }\end{array}$ & $613(56.4)$ & $474(43.6)$ \\
\hline 13 & $\begin{array}{l}\text { A person who intakes or uses more salt }(>5 \mathrm{~g}) \text { in his meals has } \\
\text { high risk of onset of Type II diabetes. }\end{array}$ & $308(28.3)$ & 779 (71.7) \\
\hline 14 & $\begin{array}{l}\text { A person who eats 2-3 serving of vegetables daily has less } \\
\text { chance of onset of type II diabetes }\end{array}$ & $932(85.7)$ & $155(14 \cdot 3)$ \\
\hline 15 & $\begin{array}{l}\text { A person who eats 2-3 serving of fruits daily has less chance of } \\
\text { onset of type II diabetes. }\end{array}$ & $549(50.5)$ & $538(49.5)$ \\
\hline 16 & $\begin{array}{l}\text { A married woman who has diabetes during pregnancy has } \\
\text { more risk of onset of Type II diabetes in the future. }\end{array}$ & 977 (89.9) & $110(10.1)$ \\
\hline 17 & $\begin{array}{l}\text { A person who faces more stress has high risk of onset of Type } \\
\text { II diabetes. }\end{array}$ & $407(37.4)$ & $680(62.6)$ \\
\hline 18 & $\begin{array}{l}\text { A person who smokes regularly has high risk of onset of Type } \\
\text { II diabetes. }\end{array}$ & $409(37.6)$ & $678(62.4)$ \\
\hline 19 & $\begin{array}{l}\text { A person who drinks more alcohol has high risk of onset of } \\
\text { Type II diabetes. }\end{array}$ & $471(43 \cdot 3)$ & $616(56.7)$ \\
\hline 20 & $\begin{array}{l}\text { A person who does not take breakfast regularly has more risk } \\
\text { of onset of Type II diabetes. }\end{array}$ & $524(48.2)$ & $563(51.8)$ \\
\hline 21 & $\begin{array}{l}\text { A person who has impaired glucose tolerance has high risk of } \\
\text { onset of Type II diabetes }\end{array}$ & $959(88.2)$ & $128(11.8)$ \\
\hline 22 & $\begin{array}{l}\text { A person who has low birth weight has high risk of onset of } \\
\text { Type II diabetes in the future. }\end{array}$ & $918(84.5)$ & $169(15.5)$ \\
\hline 23 & $\begin{array}{l}\text { A person who has high cholesterol level has high risk of onset } \\
\text { of Type II diabetes. }\end{array}$ & $526(48.4)$ & $561(51.6)$ \\
\hline 24 & $\begin{array}{l}\text { A person who eats fast food (pizza, burger, sandwich, chicken } \\
\text { nuggets, french fries etc) has high risk of onset of Type II } \\
\text { diabetes. }\end{array}$ & $439(404)$ & $649(59.6)$ \\
\hline
\end{tabular}


Knowledge about sign and symptoms of T2D among respondents were poor. More than $50 \%$ of the respondents incorrectly answered on the questions- weight gain, less feeling of thrust ad hunger, blurred vision, rapid healing of wounds, numbness in hands and feet, skin infection and decrease sexual ability. They did not consider them sings and symptoms of T2D (Table 3).

Table 3: Responses of Participants Regarding Knowledge of Sign and symptoms of Diabetes

\begin{tabular}{|c|c|c|c|}
\hline \multirow{2}{*}{ Sr. } & \multirow{2}{*}{ Statements } & Incorrect responses & Correct responses \\
\hline & & $f(\%)$ & $f(\%)$ \\
\hline 1 & Weight gain & $859(79)$ & $228(21)$ \\
\hline 2 & Less insulin production & $520(47.8)$ & $567(52.2)$ \\
\hline 3 & Less urination & $641(59)$ & $446(41)$ \\
\hline 4 & Less feeling of thirst & $700(64.4)$ & $387(35.6)$ \\
\hline 5 & Less feeling of hunger & $647(59.5)$ & $440(40.5)$ \\
\hline 6 & Blurred vision & $663(61)$ & $424(39)$ \\
\hline 7 & Rapid healing of wound & $575(52.9)$ & $512(47.1)$ \\
\hline 8 & Numbness in hands and feet & $586(53.9)$ & $501(46.1)$ \\
\hline 9 & Feeling of weakness & $379(34.9)$ & $708(65.1)$ \\
\hline 10 & Skin infection & $606(55.7)$ & $481(44 \cdot 3)$ \\
\hline 11 & Decrease sexual ability & $712(65 \cdot 5)$ & $375(34 \cdot 5)$ \\
\hline
\end{tabular}

The knowledge of impact of diabetes on diabetic patients was also less among the respondents and they did not consider eye problems, kidney problems, brain problems and liver problems as complications of diabetes (Table 4). 
Table 4: Responses of Participants Regarding Impact of Diabetes

\begin{tabular}{|l|l|l|l|}
\hline \multirow{2}{*}{ Sr. } & \multirow{2}{*}{ Statements } & Incorrect responses & Correct responses \\
\cline { 3 - 4 } & & $f(\%)$ & $f(\%)$ \\
\hline 1 & Eye problems & $586(53.9)$ & $501(46.1)$ \\
\hline 2 & Kidney problems & $578(53.2)$ & $509(46.8)$ \\
\hline 3 & Heart problems & $532(48.9)$ & $555(51.1)$ \\
\hline 4 & Brain problems & $739(68)$ & $348(32)$ \\
\hline 5 & Blood pressure & $432(39.7)$ & $655(60.3)$ \\
\hline 6 & Liver problems & $882(81.1)$ & $205(18.9)$ \\
\hline 7 & Infections & $426(39.2)$ & $661(60.8)$ \\
\hline 8 & Reduce life expectancy & $539(496)$ & $548(50.4)$ \\
\hline
\end{tabular}

The level of knowledge of risk factors showed that only $22 \%$ respondents had adequate knowledge of T2D. The level of knowledge of signs and symptoms of diabetes showed that one fourth (26.6\%) respondents had adequate knowledge of T2D. Lastly, level of knowledge of impact of diabetes highlighted that $27.8 \%$ respondents had adequate knowledge of diabetes (Figure 1).

\section{Percentage of Level of Knowledge of Diabetes}

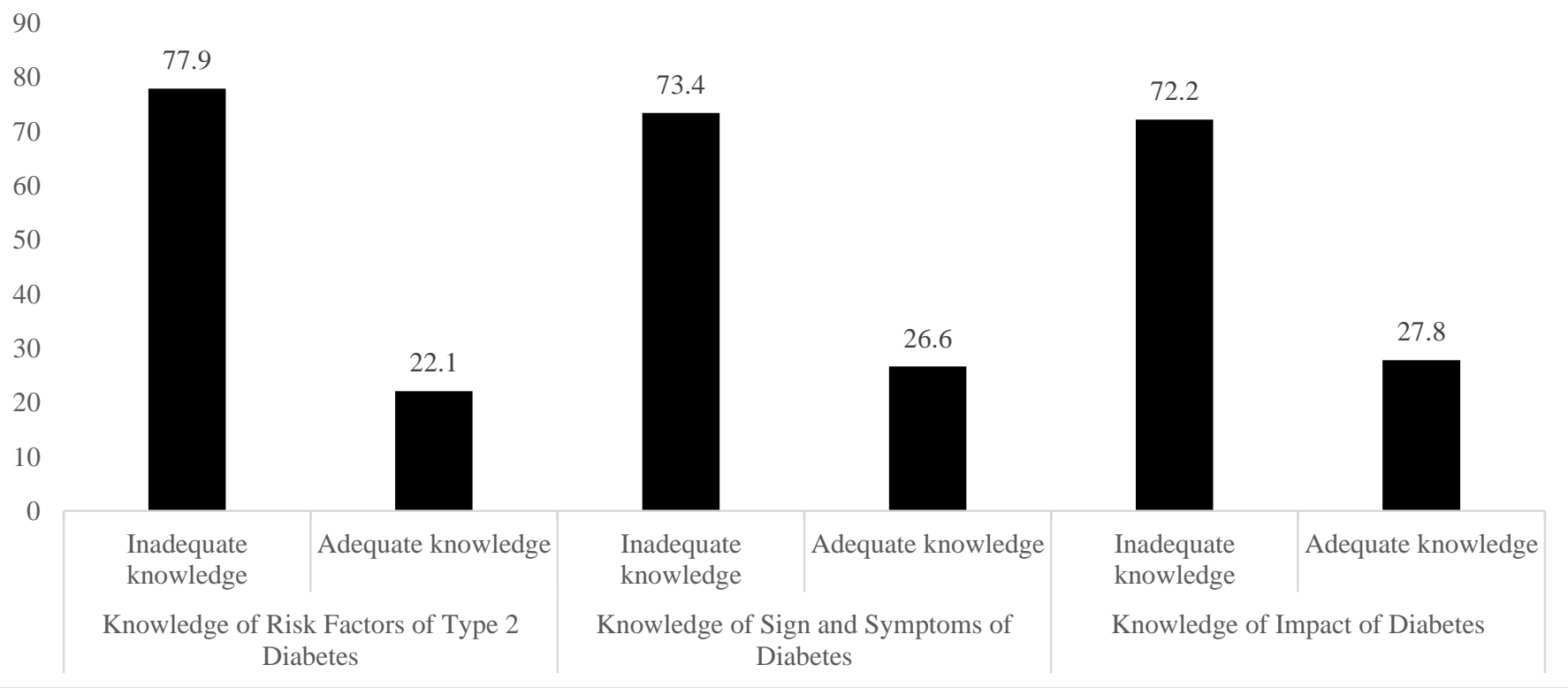

Figure 1 Percentage of Level of Knowledge of Diabetes 
Chi-square test showed that level of knowledge of diabetes was significantly associated with gender $(\mathrm{p}<.001)$, education $(\mathrm{p}<.001)$, marital status $(\mathrm{p}<.001)$, ever checking of blood sugar $(\mathrm{p}<$ $.001)$, and family history of diabetes $(\mathrm{p}<.001)$ (Table 5$)$.

Table 5: Association of Level of Knowledge of Diabetes with Demographic Characteristics of the Respondents $(n=1087)$

\begin{tabular}{|c|c|c|c|}
\hline \multirow{2}{*}{ Variables } & $\begin{array}{l}\text { Inadequate } \\
\text { Knowledge }\end{array}$ & Adequate Knowledge & Chi square \\
\hline & $\mathrm{f}(\%)$ & f $(\%)$ & \\
\hline Gender & & & $14 \cdot 7^{* * *}$ \\
\hline Male & $388(71.3)$ & $156(28.7)$ & \\
\hline Female & $441(81.2)$ & $102(18.8)$ & \\
\hline Age (years) & & & 3.7 \\
\hline Less than 20 & $245(75.6)$ & $79(24.4)$ & \\
\hline $20-23$ & $481(78)$ & $136(22)$ & \\
\hline $24-29$ & $103(70.5)$ & $43(29.5)$ & \\
\hline Education & & & $17 \cdot 3^{* * *}$ \\
\hline Intermediate & $230(73.2)$ & $84(26.8)$ & \\
\hline Undergraduate & $473(80.3)$ & $116(19.7)$ & \\
\hline Graduate & $99(72.3)$ & $38(27.7)$ & \\
\hline M.Phil./PhD & $27(57 \cdot 4)$ & $20(42.6)$ & \\
\hline Economic Status & & & .37 \\
\hline Poor & $335(77)$ & $100(23)$ & \\
\hline Middle & $324(76.2)$ & $101(23.8)$ & \\
\hline Rich & $170(74.9)$ & $57(25.1)$ & \\
\hline Marital Status & & & $7.04^{* \star}$ \\
\hline Single & $777(77.2)$ & $229(22.8)$ & \\
\hline Married & $52(64.2)$ & $29(35.8)$ & \\
\hline Ever Check Sugar & & & $19.6 * * *$ \\
\hline No & $647(79.6)$ & $166(20.4)$ & \\
\hline Yes & $182(66.4)$ & $92(33.6)$ & \\
\hline Family History of Diabetes & & & $7 \cdot 30^{* * *}$ \\
\hline No & $549(78.9)$ & $147(21.1)$ & \\
\hline Yes & $280(71.6)$ & $111(28.4)$ & \\
\hline
\end{tabular}




\section{Discussion}

The findings of the study showed that university students had inadequate knowledge about T2D diabetes with the frequencies of correct answers being less than $50 \%$ in the following areas: its risk factors like family history of diabetes, abdominal fat, less physical activity, sleep less than 7-8 hours, aging, poor dietary patterns, and daily vegetable consumption; its signs and symptoms like less feeling of thrust, blurred vision, numbness in hands and feet, decreased sexual ability; and its impact like eye problems, brain problems, kidney problems. In addition, demographic characteristics of the university students like gender was significantly associated with level of knowledge about diabetes and in it males had higher knowledge than females. Studies conducted in Pakistan and other countries also showed the same finding that males had more diabetes knowledge than females (Soltanian, Bahreini, \& AfkhamiArdekani, 2007; ur Rehman et al., 2014).

Level of education of the respondents was statistically significantly associated with level of diabetes knowledge. And the respondents who had higher education were more aware about the diabetes risk factors, sign and symptoms and its impacts. The previous studies supported this finding that the people with more educated have higher level of knowledge about diabetes (Foma, Saidu, Omoleke, \& Jafali, 2013; Soltanian et al., 2007; Ulvi et al., 2009). Age group of the respondents did not significant association with level of knowledge of diabetes but the finding showed that respondents between 23-29 years old were more aware about diabetes risk factors but their percentage was very low. A study conducted in Pakistan had the same finding and showed that respondents having age more than 20 years had adequate knowledge of diabetes (Masood et al., 2016).

Economic status of the respondents was not associated with level of knowledge in this study. The previous study mentioned that individuals who belonged to higher income group had more diabetes knowledge score as compared to low-income group individuals (Masood et al., 2016; Sabri, Qayyum, Saigol, Zafar, \& Aslam, 2007). Furthermore, it might be due to lack of seriousness and perceived susceptibility of the disease among this age group. It was observed that marital status of the respondents was associated with level of knowledge and respondents who were married had higher level of knowledge of diabetes. The finding of the study was aligned with the study conducted on university students in Saudi Arabia that marital status of the students were statistically associated with level of knowledge of diabetes (Alamri, 2021)

The current study as well as earlier studies revealed that family history of diabetes was significantly associated with level of knowledge of diabetes among university students (AmankwahPoku, 2019; N. Khan et al., 2012). The study findings also indicated that mostly students reported that family history was not a risk factor of diabetes onset. It might be due to no family member with diabetes and that's why they had low knowledge of diabetes and risk perception as compared to students who had family history of diabetes (Mongiello et al., 2016).

The findings also indicated that the level of knowledge of diabetes was associated with ever blood sugar. The respondents who ever checked blood sugar had higher knowledge of T2D as compared to respondents who did not ever check blood sugar. A study conducted on university students mentioned that students who checked blood sugar had more diabetes knowledge score (Gazzaz, 2020). Earlier study showed that poor knowledge about T2D among the young adults was common, so efforts to decrease the frequency of T2D must include young adults who are at susceptible age and can be inspired to adopt positive health behaviors (Al-Mahrooqi et al., 2013). It was observed that lack of knowledge about diabetes was one of many factors which had made the T2D burden worse. 
From the last two decades, the prevalence of diabetes among young adults increased rapidly due to lifestyle and socioeconomic changes (Wild et al., 2004). Taking immediate measures is of equal importance targeting university students to enhance awareness about diabetes from the public health approach. The previous studies have been revealed that $80 \%$ of $\mathrm{T} 2 \mathrm{D}$ cases might be reduced by changing health behaviors like eating healthy diet and enhancing regular exercise and physical activity (Atlas, 2015; Galaviz, Narayan, Lobelo, \& Weber, 2018).

However, this study found that only $42.5 \%$ of the respondents recognized that less physical activity and $43.6 \%$ of the respondents recognized that poor dietary pattern was risk factors of T2D onset. This situation is alarming because physical inactivity and unhealthy eating behaviors are common among youth in Pakistan (Imtiaz, ulHaq, Afaq, Khan, \& Gillani, 2020). Evidence recommended that individuals who had high knowledge adopted healthier lifestyle were able to delay or prevent the onset of T2D (Okosun, Davis-Smith, \& Seale, 2012). The study recommended that it is a need of the time to increase awareness and knowledge of diabetes risk factors and to develop models of health education and behavior change that are effective and relevant to university students (Mongiello et al., 2016).

\section{Conclusion}

The findings of the study showed shown that one fourth of the respondents had adequate knowledge of diabetes about its risk factors, sign and symptoms, and complication. Gender, marital status, blood glucose testing and family history of diabetes were associated with higher knowledge among the students. Lack of knowledge was common among all the respondents. These findings of the study demonstrated the urgent need of awareness programs and attention of medical professional and policy makers to take critical steps in decreasing the epidemic of diabetes in Pakistan.

\section{Referneces}

Abate, N., \& Chandalia, M. (2001). Ethnicity and type 2 diabetes: focus on Asian Indians. Journal of Diabetes and its Complications, 15(6), 320-327.

Abate, N., \& Chandalia, M. (2003). The impact of ethnicity on type 2 diabetes. Journal of Diabetes and its Complications, 17(1), 39-58.

Al-Mahrooqi, B., Al-Hadhrami, R., Al-Amri, A., Al-Tamimi, S., Al-Shidhani, A., Al-Lawati, H., . . . AlGhafri, T. (2013). Self-reported knowledge of diabetes among high school students in Al-Amerat and Quriyat, Muscat Governate, Oman. Sultan Qaboos University Medical Journal, 13(3), 392.

Alamri, O. (2021). Knowledge of Diabetes Characteristics by Students at University of Tabuk, Saudi Arabia. Health, 13(4), 393-404.

Alberti, K. G. M. M., Zimmet, P., \& Shaw, J. (2007). International Diabetes Federation: a consensus on Type 2 diabetes prevention. Diabetic Medicine, 24(5), 451-463.

Alneami, Y. M., \& Coleman, C. L. (2016). Risk factors for and barriers to control type-2 diabetes among Saudi population. Global journal of health science, 8(9), 10.

Amankwah-Poku, M. (2019). A cross-sectional study of knowledge and awareness of type 2 diabetes mellitus in a student population in Ghana: do demographics and lifestyle make a difference. Health Psychology and Behavioral Medicine, 7(1), 234-252.

Asif, M. (2014). The prevention and control the type-2 diabetes by changing lifestyle and dietary pattern. Journal of education and health promotion, 3 .

Association, A. D. (2021). 3. Prevention or delay of type 2 diabetes: standards of medical care in diabetes-2021. Diabetes care, 44(Supplement 1), S34-S39.

Atlas, D. (2015). International diabetes federation. IDF Diabetes Atlas, $7^{\text {th }}$ edn. Brussels, Belgium: 
International Diabetes Federation.

Ballon, A., Neuenschwander, M., \& Schlesinger, S. (2019). Breakfast skipping is associated with increased risk of type 2 diabetes among adults: A systematic review and meta-analysis of prospective cohort studies. The Journal of nutrition, 149(1), 106-113.

Basit, A., Fawwad, A., \& Baqa, K. (2019). Pakistan and diabetes-A country on the edge. Diabetes research and clinical practice, $147,166-168$.

Basit, A., Fawwad, A., Qureshi, H., \& Shera, A. (2018). Prevalence of diabetes, pre-diabetes and associated risk factors: second National Diabetes Survey of Pakistan (NDSP), 2016-2017. BMJ open, 8(8), e020961.

Chow, E. A., Foster, H., Gonzalez, V., \& McIver, L. (2012). The disparate impact of diabetes on racial/ethnic minority populations. Clinical Diabetes, 30(3), 130-133.

Duncan, G. E. (2006). Prevalence of diabetes and impaired fasting glucose levels among US adolescents: National Health and Nutrition Examination Survey, 1999-2002. Archives of pediatrics \& adolescent medicine, $160(5)$, 523-528.

Dunkley, A. J., Bodicoat, D. H., Greaves, C. J., Russell, C., Yates, T., Davies, M. J., \& Khunti, K. (2014). Diabetes prevention in the real world: effectiveness of pragmatic lifestyle interventions for the prevention of type 2 diabetes and of the impact of adherence to guideline recommendations: a systematic review and meta-analysis. Diabetes care, 37(4), 922-933.

Engelgau, M. M., Narayan, K., \& Herman, W. H. (2000). Screening for type 2 diabetes. Diabetes care, 23(10), 1563-1580.

Federation, I. D. (2011). The global burden. IDF Diabetes Atlas. In.

Foma, M. A., Saidu, Y., Omoleke, S. A., \& Jafali, J. (2013). Awareness of diabetes mellitus among diabetic patients in the Gambia: a strong case for health education and promotion. BMC public health, 13(1), 1-8.

Galaviz, K. I., Narayan, K. V., Lobelo, F., \& Weber, M. B. (2018). Lifestyle and the prevention of Type 2 Diabetes: a status report. American journal of lifestyle medicine, 12(1), 4-20.

Gale, E. A., \& Gillespie, K. M. (2001). Diabetes and gender. Diabetologia, 44(1), 3-15.

Gazzaz, Z. J. (2020). Knowledge, attitudes, and practices regarding diabetes mellitus among university students in Jeddah, Saudi Arabia. Diabetes, Metabolic Syndrome and Obesity: Targets and Therapy, 13, 5071.

Gillani, A. H., Amirul Islam, F. M., Hayat, K., Atif, N., Yang, C., Chang, J., . . . Fang, Y. (2018). Knowledge, attitudes and practices regarding diabetes in the general population: A crosssectional study from Pakistan. International journal of environmental research and public health, 15(9), 1906.

Gitu, A. C. (2018). Is poor sleep a risk factor for type 2 diabetes? Evidence-Based Practice, 21(9), 52-53.

Harris, M. L., Oldmeadow, C., Hure, A., Luu, J., Loxton, D., \& Attia, J. (2017). Stress increases the risk of type 2 diabetes onset in women: A 12-year longitudinal study using causal modelling. PloS one, $12(2)$, eo172126.

Health, U. D. o., \& Services, H. (2014). The health consequences of smoking-50 years of progress: a report of the Surgeon General. In: Atlanta, GA: US Department of Health and Human Services, Centers for Disease ....

Hussain, A., \& Ali, I. (2016). Diabetes mellitus in Pakistan: A major public health concern. Archives of Pharmacy Practice, 7(1), 30-33.

Imtiaz, A., ulHaq, Z., Afaq, S., Khan, M. N., \& Gillani, B. (2020). Prevalence and patterns of physical activity among school aged adolescents in Pakistan: a systematic review and meta-analysis. International Journal of Adolescence and Youth, 25(1), 1036-1057.

Jornayvaz, F. R., Vollenweider, P., Bochud, M., Mooser, V., Waeber, G., \& Marques-Vidal, P. (2016). Low birth weight leads to obesity, diabetes and increased leptin levels in adults: the CoLaus study. 
Cardiovascular diabetology, 15(1), 1-10.

Kao, W. L., Puddey, I. B., Boland, L. L., Watson, R. L., \& Brancati, F. L. (2001). Alcohol consumption and the risk of type 2 diabetes mellitus: atherosclerosis risk in communities study. American journal of epidemiology, 154(8), 748-757.

Katulanda, P., Constantine, G. R., Weerakkody, M. I., Perera, Y. S., Jayawardena, M. G., Wijegoonawardena, P., . . . Sheriff, M. H. (2011). Can we bridge the gap? Knowledge and practices related to Diabetes Mellitus among general practitioners in a developing country: a cross sectional study. Asia Pacific Family Medicine, 10(1), 1-6.

Khan, N., Gomathi, K. G., Shehnaz, S. I., \& Muttappallymyalil, J. (2012). Diabetes mellitus-related knowledge among university students in Ajman, United Arab Emirates. Sultan Qaboos University Medical Journal, 12(3), 306.

Khan, R. M. A., CH, T. S., \& Ahmad, M. (2009). Assessment of awareness about diabetes mellitus among adult populace of lahore: a preventive approach required to combat the disease in Pakistan. Age, 40(75), 75 .

Khatib, O. (2004). Noncommunicable diseases: risk factors and regional strategies for prevention and care. EMHJ-Eastern Mediterranean Health Journal, 10 (6), 778-788, 2004.

Khosa, Z., Mukhtar Mehboob, M. Z., Sana, H., \& Khosa, A. Z. Medical Students and Type 2 Diabetes Mellitus: Knowledge and Approach.

Kim, C., Newton, K. M., \& Knopp, R. H. (2002). Gestational diabetes and the incidence of type 2 diabetes: a systematic review. Diabetes care, 25(10), 1862-1868.

Kim, M.-J., Lim, N.-K., Choi, S.-J., \& Park, H.-Y. (2015). Hypertension is an independent risk factor for type 2 diabetes: the Korean genome and epidemiology study. Hypertension Research, 38(11), 783-789.

Lee, S., Bacha, F., \& Arslanian, S. A. (2006). Waist circumference, blood pressure, and lipid components of the metabolic syndrome. The Journal of pediatrics, 149(6), 809-816.

Li, M., Fan, Y., Zhang, X., Hou, W., \& Tang, Z. (2014). Fruit and vegetable intake and risk of type 2 diabetes mellitus: meta-analysis of prospective cohort studies. BMJ open, 4(11), e005497.

Mangi, A. A., Khan, H., Junno, A. A., Nindwani, R. A., Yousuf, M., \& Shehanshah, M. (2018). Knowledge, Attitude and Practice about diabetes among diabetic patients in Sindh, Pakistan. Rawal Medical Journal, 43(1), 4-7.

Masood, I., Saleem, A., Hassan, A., Zia, A., \& Khan, A. T. (2016). Evaluation of diabetes awareness among general population of Bahawalpur, Pakistan. Primary care diabetes, 10(1), 3-9.

Mathers, C. D., \& Loncar, D. (2006). Projections of global mortality and burden of disease from 2002 to 2030. PLoS medicine, 3(11), e442.

Mongiello, L. L., Freudenberg, N., Jones, H., \& Spark, A. (2016). Many college students underestimate diabetes risk. Journal of allied health, 45(2), 81-86.

Nathan, D. M. (1993). Long-term complications of diabetes mellitus. New England journal of medicine, 328(23), 1676-1685.

Nathan, D. M., Davidson, M. B., DeFronzo, R. A., Heine, R. J., Henry, R. R., Pratley, R., \& Zinman, B. (2007). Impaired fasting glucose and impaired glucose tolerance: implications for care. Diabetes care, 30(3), 753-759.

Okosun, I. S., Davis-Smith, M., \& Seale, J. P. (2012). Awareness of diabetes risks is associated with healthy lifestyle behavior in diabetes free American adults: evidence from a nationally representative sample. Primary care diabetes, 6(2), 87-94.

Panagiotakos, D. B., Tzima, N., Pitsavos, C., Chrysohoou, C., Papakonstantinou, E., Zampelas, A., \& Stefanadis, C. (2005). The relationship between dietary habits, blood glucose and insulin levels among people without cardiovascular disease and type 2 diabetes; the ATTICA study. The Review of Diabetic Studies, 2(4), 208. 
Phil, S. H. M., \& Hafeez, M. (2016). Assessment of Diabetes Related Knowledge Amongst Pre-Clinical Medical \& Dental Students of IMDC. Length Elongation in Chinese Children with Myopia, 14(1), 61.

Pouwer, F., Kupper, N., \& Adriaanse, M. C. (2010). Does emotional stress cause type 2 diabetes mellitus? A review from the European Depression in Diabetes (EDID) Research Consortium. Discovery medicine, 9(45), 112-118.

Radzeviciene, L., \& Ostrauskas, R. (2017). Adding salt to meals as a risk factor of type 2 diabetes mellitus: a case-control study. Nutrients, 9(1), 67.

Ramachandran, A. (2014). Know the signs and symptoms of diabetes. The Indian journal of medical research, $140(5), 579$.

Ramkumar, S., \& Tandon, N. (2013). Type 2 diabetes mellitus in children and youth. The Indian Journal of Pediatrics, 8o(1), 87-94.

Sabri, A. A., Qayyum, M. A., Saigol, N. U., Zafar, K., \& Aslam, F. (2007). Comparing knowledge of diabetes mellitus among rural and urban diabetics. McGill Journal of Medicine: MJM, 10(2), 87.

Seo, M. H., Bae, J. C., Park, S. E., Rhee, E. J., Park, C. Y., Oh, K. W., . . . Lee, W.-Y. (2011). Association of lipid and lipoprotein profiles with future development of type 2 diabetes in nondiabetic Korean subjects: a 4-year retrospective, longitudinal study. The Journal of Clinical Endocrinology \& Metabolism, 96(12), E2050-E2054.

Shahzad, A., Ahmad, M. M., Anwer, I., Ijaz, N., Shahzad, M., \& Usman, M. (2018). Gender-specific Knowledge of Diabetes and Its Management Among Patients Visiting Outpatient Clinics in Faisalabad, Pakistan. Cureus, 10(8).

Soltanian, A. R., Bahreini, F., \& Afkhami-Ardekani, M. (2007). People awareness about diabetes disease and its complications among aged 18 years and older in Bushehr port inhabitants (Iran). Diabetes \& Metabolic Syndrome: Clinical Research \& Reviews, 1(4), 245-249.

Sridhar, G., Putcha, V., \& Lakshmi, G. (2010). Time trends in the prevalence of diabetes mellitus: Ten year analysis from southern India (1994-2004) on 19,072 subjects with diabetes. Japi, 58, 291.

Ulvi, O. S., Chaudhary, R. Y., Ali, T., Alvi, R. A., Khan, M., Khan, M., . . Shahid, T. (20og). Investigating the awareness level about diabetes mellitus and associated factors in Tarlai (rural Islamabad). JPMA. The Journal of the Pakistan Medical Association, 59(11), 798-801.

ur Rehman, Z., Irshad, M., Khan, I., Khan, F. A., Baig, A., \& Gaohar, Q. Y. (2014). A survey of awareness regarding Diabetes and its Management among patients with Diabetes in Peshawar, Pakistan. Journal of Postgraduate Medical Institute (Peshawar-Pakistan), 28(4).

Valdez, R., Yoon, P. W., Liu, T., \& Khoury, M. J. (2007). Family history and prevalence of diabetes in the US population: the 6-year results from the National Health and Nutrition Examination Survey (1999-2004). Diabetes care, 30(10), 2517-2522.

Villegas, R., Shu, X. O., Gao, Y.-T., Yang, G., Elasy, T., Li, H., \& Zheng, W. (2008). Vegetable but not fruit consumption reduces the risk of type 2 diabetes in Chinese women. The Journal of nutrition, 138(3), 574-580.

Wada, M., Yano, S., Hamano, T., Nabika, T., \& Kumakura, S. (2016). Effect of serum cholesterol on insulin secretory capacity: Shimane CoHRE Study. PloS one, 11(2), e0149452.

Wild, S., Roglic, G., Green, A., Sicree, R., \& King, H. (2004). Global prevalence of diabetes: estimates for the year 2000 and projections for 2030. Diabetes care, 27(5), 1047-1053.

Zuhaid, M., Zahir, K. K., \& Diju, I. U. (2012). Knowledge and perceptions of diabetes in urban and semi urban population of Peshawar, Pakistan. Journal of Ayub Medical College Abbottabad, 24(1), 105108. 